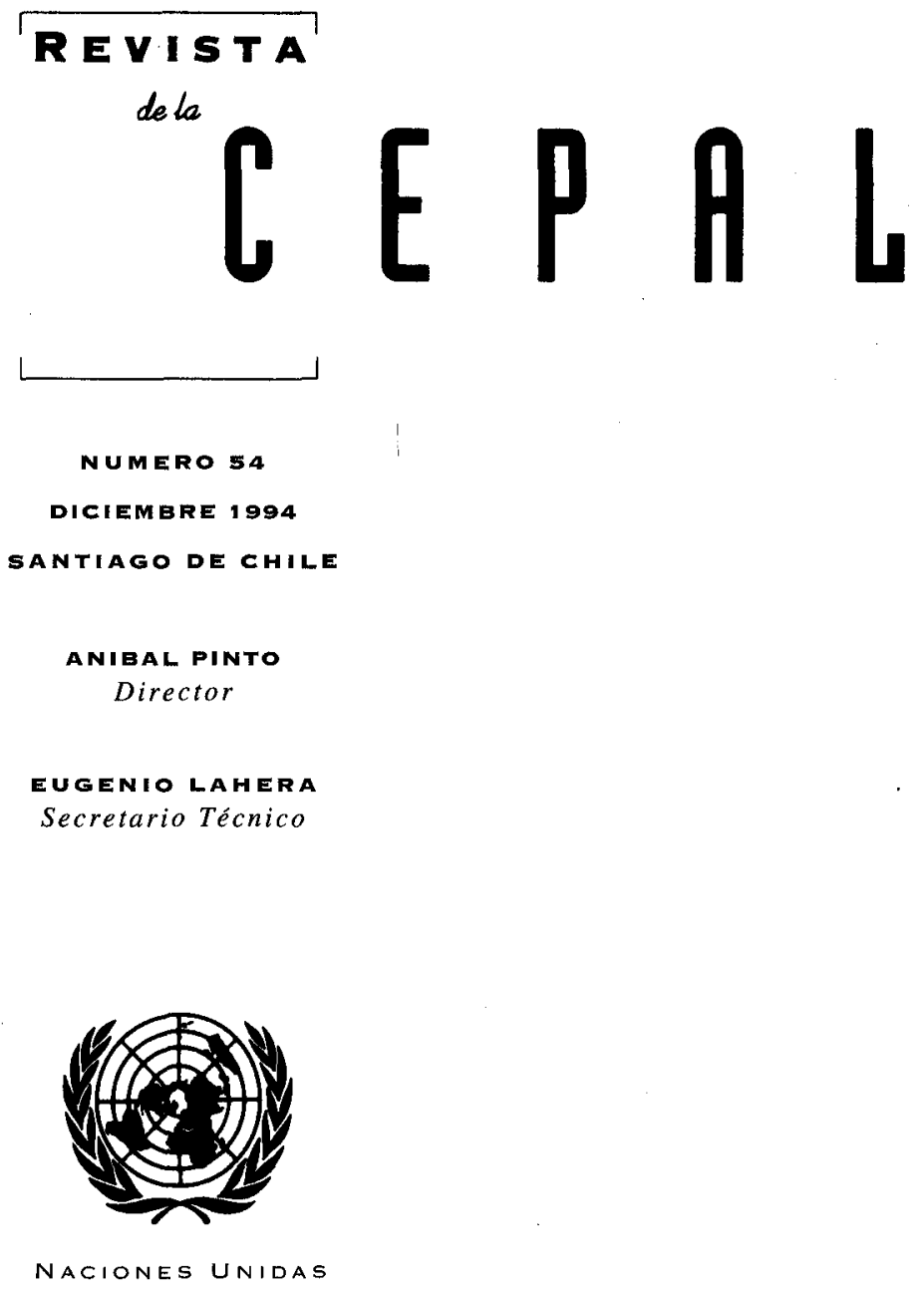


Mercados de salud: morfología, comportamiento y regulación

Jorge Katz y Ernesto Miranda

¿Liberalización o desarrollo financiero?

Günther Held

Ajuste fiscal y gasto social

Rossella Cominetti

Logros y obstáculos en la educación formal de las mujeres

Diane Alméras

¿Qué se entiende por flexibilidad del mercado de trabajo?

Ricardo A. Lagos

Modernización de la supervisión bancaria

Christian Larraín

Costos y beneficios de la integración centroamericana

Luis Cáceres

Algunas enseñanzas de las privatizaciones en Argentina

Daniel Azpiazu y Adolfo Vispo

Ventajas comparativas extraordinarias y crecimiento a largo plazo:

el caso de Ecuador

André A. Hofman y Rudolf Buitelaar

Industria cultural y nuevos códigos de modernidad

Martín Hopenhayn

Orientaciones para los colaboradores de la Revista de la CEPAL

Publicaciones recientes de la CEPAL 


\section{Logros y obstáculos en la educación formal de las mujeres}

\section{Diane Alméras}

Oficial de Asuntos Sociales de la Unidad Mujer y Desarrollo de la CEPAL.
El examen de la educación de las mujeres en la región lleva a conclusiones aparentemente contradictorias: por una parte, ha habido logros reales en términos de cobertura y de rendimiento, lo que permite sostener que el impulso hacia la igualdad de oportunidades de acceso está dado allí donde ésta aún no se ha obtenido y que la situación seguirá mejorando. Pero por otra parte, del análisis de los datos surgen comprobaciones menos positivas que justifican una continuada preocupación por el tema. Además de los problemas estructurales que persisten en la mayoría de los sistemas de educación formal del continente y que limitan la expansión de la cobertura educativa para hombres y mujeres, desde hace casi dos décadas se viene señalando en estudios y diagnósticos que el proceso educativo de las mujeres está estrechamente ligado a la discriminación de género adoptada como norma por el ethos cultural latinoamericano, tanto para los contenidos educacionales como para las oportunidades profesionales. Este artículo busca poner en contrapeso los datos más recientes sobre el acceso de las mujeres a la educación formal en términos cuantitativos y los obstáculos a una verdadera igualdad de oportunidades con que éstas tropiezan en los sistemas educativos. 


\section{I}

\section{Introducción}

Los estudios sobre la educación formal en América Latina y el Caribe destacan desde hace ya muchos años los notables avances de los países de la región en su lucha contra el analfabetismo y en el mejoramiento de las tasas de escolaridad a todos los niveles, con un aumento constante de la participación de las mujeres (CEPAL, 1984, 1988 y 1991b) hasta superar la de los hombres en varios países. No obstante, pese a esta imagen en general positiva, persisten en los procesos educativos problemas estructurales graves, con una gran heterogeneidad de situaciones nacionales y, dentro de los países, con pirámides socioeducativas muy estratificadas, en virtud de diferencias étnicas, regionales y socioeconómicas (Valdés y Gomariz, 1992 y 1993). Para las mujeres de la región esto ha significado el mantenimiento de altas tasas de analfabetismo en las áreas rurales, entre las mujeres indígenas y en las cohortes de edades mayores. ${ }^{1}$

En el pasado, las lagunas de los sistemas educativos en la región han dependido tanto "de las estrategias globales de desarrollo" adoptadas por los países como de "las diferentes posibilidades de los distintos grupos sociales para acceder a esos sistemas y permanecer en ellos" (CEPAL, 1990). Puesto que por su tradicional situación subordinada en la sociedad las mujeres quedaron fuera de las esferas de poder que les hubieran permitido influir en tales estrategias de desarrollo, su integración en los procesos de educación formal ha dado lugar a un conjunto de situaciones complejas producidas por el cruce de las distintas variables de sexo, edad, clase social, etnia y área geográfica.
Si hoy la igualdad de acceso a los sistemas educativos parece ser una realidad para los y las jóvenes de menos de 25 años, la discriminación de las mujeres subsiste en cuanto a los aspectos cualitativos de la educación. Ya en los años ochenta se empezó a denunciar las limitaciones a la integración de las mujeres en los procesos educativos que las llevan a concentrarse, principalmente a nivel de la educación superior, en áreas consideradas en los últimos años de "interés femenino", tales como educación, ciencias sociales, bellas artes y ciertas áreas de la medicina (CEPAL, 1984, 1988 y 1991b). También son ahora temas reconocidos y analizados de manera creciente los efectos de los estereotipos sexuales en los contenidos de la enseñanza y de los sesgos discriminativos de la orientación vocacional en el proyecto de vida de las mujeres. En otras palabras, a medida que se allanan las dificultades para que las mujeres se integren a la educación, el problema ya no es "cuántas mujeres estudian, sino qué estudian y cuál es la calidad de la educación y el ambiente de estudio" (Bonilla Castro, 1991).

Es preciso entonces ir más allá de las observaciones cuantitativas sobre las oportunidades de acceso de las mujeres al sistema de educación formal, y examinar la naturaleza de los problemas estructurales que afectan la relación varones/mujeres en las tasas de escolarización; los factores socioculturales que intervienen en los contenidos del material de enseñanza; el papel de los docentes en la construcción y reproducción de las identidades de género, y el efecto de la división sexual del trabajo vigente sobre las oportunidades vocacionales. $\square$ La autora agradece la colaboración de María-Luisa Jáuregui (UNESCO) en la elaboración de los datos relativos al analfabetismo, la educación preescolar y primaria, la bilingüe intercultural y la técnica. También fueron indispensables los comentarios de Miriam Krawczyk, Irma Arriagada, Molly Pollack, Nieves Rico, Pauline van der Aa y María Rebecca Yañez, colegas y expertas cercanas al trabajo de la Unidad Mujer y Desarrollo de la CEPAL.

- Cabe señalar aquí un problema muy conocido en la región: la poca comparabilidad de los datos que provienen de censos realizados en distintos años, que corresponden a poblaciones de edades diversas y que se refieren a una distribución de los años escolares a través del sistema de educación formal que varía de un país a otro. En muchos casos fue necesario recurrir tanto a datos de encuestas nacionales de hogares como a datos de censos, lo que limita la utilidad de los cuadros a la de un marco descriptivo y aproximado e impide su utilización como instrumento de "evaluación" en el sentido estricto de la palabra. Sin embargo, aun cuando los datos no son absolutamente comparables y no tienen una exactitud estadística total, sí son representativos de la realidad y permiten entender mejor la dirección que está tomando la situación educacional de las mujeres, así como sus consecuencias en términos sociales, políticos y culturales. 


\section{II}

\section{Algunos factores de exclusión de las mujeres}

\section{en la región}

En el contexto descrito de grandes diferencias entre los países de la región y de deficiencia en la calidad de la formación impartida, y con miras a entender mejor el significado de los logros que han tenido las nuevas generaciones de mujeres en términos de oportunidades de acceso a la educación, conviene examinar en primer lugar los factores de exclusión que las afectan particularmente y que a la vez presentan importantes desafíos a los sistemas educativos: el aislamiento de las regiones rurales, la brecha educativa entre las generaciones, la discriminación étnica y la persistencia del analfabetismo.

\section{Aislamiento de las regiones rurales}

El último Panorama social de América Latina preparado por la CEPAL (1993) informa que "los niveles educacionales de la población rural continúan siendo bajos y notablemente inferiores a los urbanos". Persisten en las áreas rurales tasas de analfabetismo claramente mayores, así como diferencias entre hombres y mujeres que exceden de manera importante las encontradas en áreas urbanas (cuadro 1). Además, contrariamente a lo que ocurre en las zonas urbanas de la mayoría de los países, las mujeres tienden a compartir en áreas rurales las altas tasas de repitencia y deserción escolar que a nivel de la región son reconocidas como propiamente masculinas (Valdés y Gomariz, 1992 y 1993).

Las diferencias se agudizan aún más cuando se toma en consideración la calidad de la educación impartida; el "currículo obligatorio de la educación básica es diseñado en las ciudades y resulta completamente inadecuado para los niños del medio rural, especialmente los de origen indígena con limitado o nulo conocimiento del español" (CEPAL/UNESCOOREALC, 1992). A esto se añaden las incompatibilidades entre las vacaciones escolares y las necesidades temporales de mano de obra, y la falta de preparación de los docentes.

Tales fallas tienen consecuencias adicionales para las niñas, que confrontan a los estereotipos discriminativos presentes en la enseñanza de profesores poco preparados para transmitir nuevos modelos educativos. También están limitadas en sus proyectos de vida por la falta de oportunidades vocacionales en una sociedad profundamente marcada por la tradicional división sexual del trabajo, como lo es la sociedad rural de los países latinoamericanos, y además por la restringida oferta laboral en el medio rural.

\section{Brecha generacional}

La importante brecha generacional que se observa hoy en los niveles educativos es el resultado directo del proceso de creciente escolarización que tuvo lugar en la región en las últimas décadas, y que ha beneficiado principalmente a las nuevas generaciones. Cuando se comparan las cifras de escolarización según el sexo, la zona y el ingreso, "las variaciones más sustanciales se registran por tramos de edad" (UNICEF/Chile, MIDEPLAN, 1993).

En el caso de las mujeres, esta situación es el indicador más claro de la magnitud de sus avances en cuanto a oportunidades de acceso a la educación formal. De hecho, las diferencias entre las condiciones educativas de las jóvenes de 15 a 24 años de edad y de las mujeres de 50 años y más son tan importantes que para describirlas sería posible hablar de distintas "biografías sociales" (CEPAL, 1994c). Así por ejemplo, en Bolivia, las cifras de analfabetismo en 1988 eran de $3.5 \%$ para las mujeres de 15 a 19 años y de $66.8 \%$ para las de 50 años y más. Esta última cifra subía a $85.9 \%$ en la zona rural (Bolivia, Coordinadora de la Mujer, 1990). En Chile, el promedio de escolaridad para las mujeres mayores de 64 años era en 1990 de seis años en zonas urbanas y de menos de tres en zonas rurales, en tanto que en las de 15 a 24 años de edad dicho promedio era de 11 y ocho años, respectivamente (UNICEF/Chile, MIDEPLAN, 1993).

Obviamente, el problema no es en sí la existencia de tal brecha, sino el hecho de que las mujeres mayores se encuentran sin educación mientras siguen viviendo en una sociedad que exige cada vez más eficiencia en el manejo de la aritmética y de la lectoescritura. Cuando se compara con la situación de 
CUADRO 1

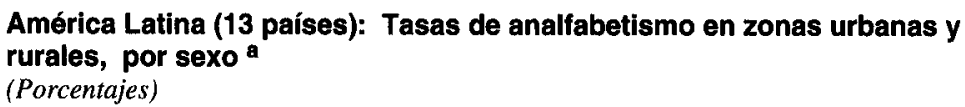

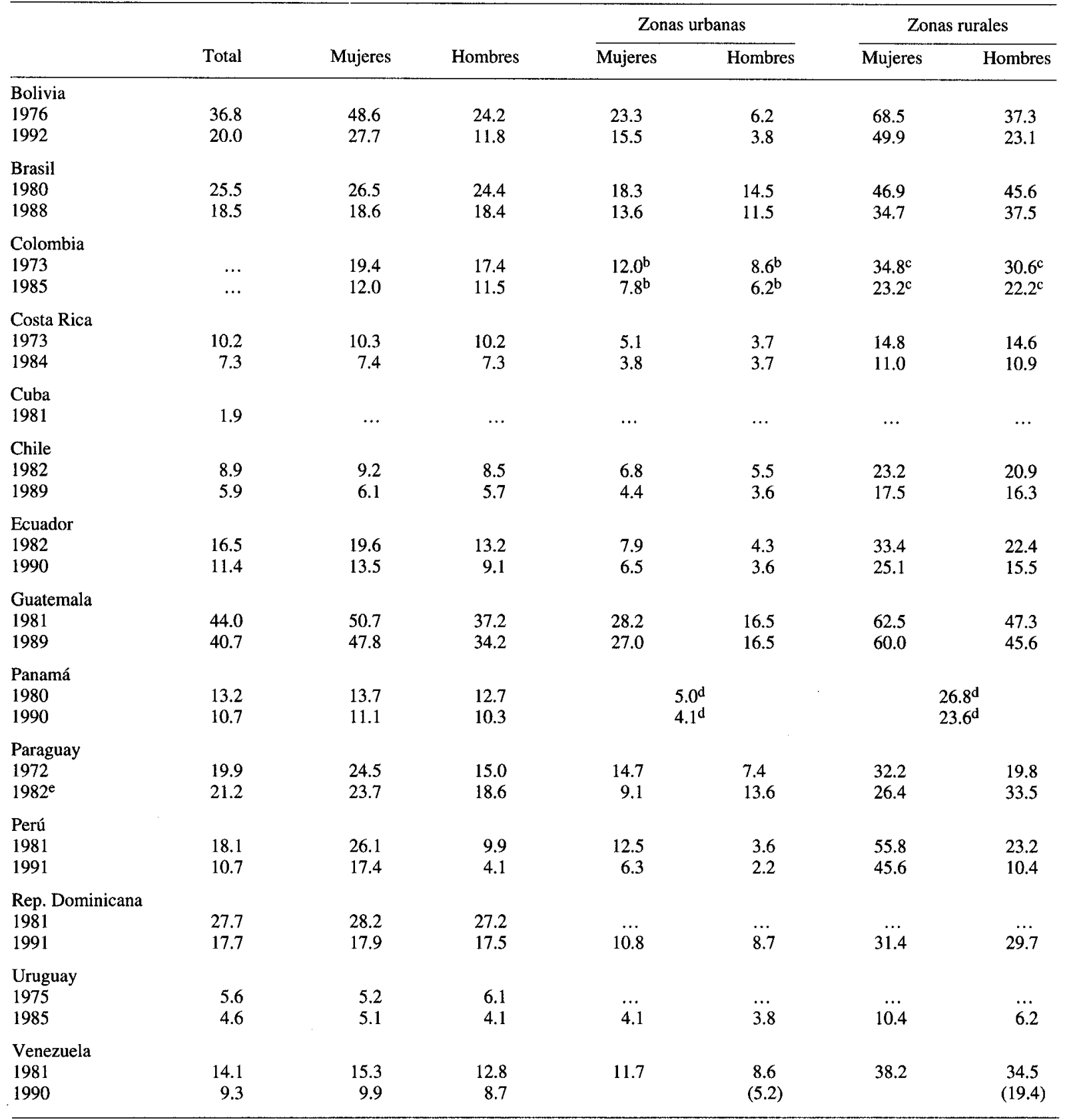

Fuente: Valdés y Gomariz (1992 y 1993).

${ }^{a}$ Corresponde a población de 15 años y más, salvo en Brasil (10 años y más); Colombia 1985 (12 años y más); Costa Rica 1973 (10 años y más); Cuba (10 a 49 años) y Panamá (10 años y más).

b Cabeceras.

c Resto del país.

d Hombres y mujeres.

e El aumento general del analfabetismo este año se debe a una forma distinta de registro en el censo de 1982; en cuanto al aumento masculino, éste tendría por causas el mayor abandono escolar de los niños y las deficiencias educativas "que arrastra una cantidad importante de los inmigrantes varones que se dirigen a ampliar la frontera agrícola y a las obras de construcción de las centrales hidroeléctricas" (Valdés y Gomariz, 1993). 
los varones, se nota de manera clara que las generaciones de mujeres mayores quedaron al margen del proceso de igualación de oportunidades del cual hoy se benefician las más jóvenes. Considerando de nuevo los casos de Bolivia y Chile, se observa que en Bolivia el $40 \%$ de los hombres de 50 años y más eran analfabetos en 1988, en comparación con el $66.8 \%$ de las mujeres, y que en Chile los hombres de 65 años y más tenían en 1990 una escolaridad media de 6.9 años en las zonas urbanas y de $\mathbf{3 . 2}$ en las zonas rurales, en tanto que los promedios para las mujeres de la misma edad eran de 6.0 y 2.7 años, respectivamente (véase también datos del cuadro 2).

\section{Discriminación étnica}

a) Situación educacional de las mujeres indígenas

En la vida diaria, y por razones obvias de comunicación y de convivencia, las dificultades de ser indígena se agudizan a través del idioma. En el caso de las mujeres, ello se traduce en tasas de analfabetismo que pueden alcanzar niveles dramáticos. Por ejemplo, en Bolivia el $95.6 \%$ de las mujeres que hablan solamente aimara y el $94.7 \%$ de las que hablan solamente el quechua no tenían instrucción formal alguna en 1988; sólo el $5.1 \%$ y el $4.4 \%$ de ellas, respectivamente, habían tenido acceso a la educación primaria.

CUADRO 2

América Latina (10 países): Tasas de analfabetismo de la población de 15 años y más, por grupos de edades y por sexo (Porcentajes)

\begin{tabular}{|c|c|c|c|c|c|c|}
\hline \multirow[b]{2}{*}{ Países } & \multicolumn{3}{|c|}{ Mujeres } & \multicolumn{3}{|c|}{ Hombres } \\
\hline & $\begin{array}{l}15-19 \\
\text { años }\end{array}$ & $\begin{array}{c}20-24 \\
\text { años }\end{array}$ & $\begin{array}{c}65 \text { años y } \\
\text { más }\end{array}$ & $\begin{array}{c}15-19 \\
\text { años }\end{array}$ & $\begin{array}{c}20-24 \\
\text { años }\end{array}$ & $\begin{array}{c}65 \text { años y } \\
\text { más }\end{array}$ \\
\hline Bolivia (1988) & 3.5 & 7.7 & 66.5 & 1.5 & 2.0 & 43.2 \\
\hline Brasil (1989) & 8.0 & 9.4 & 50.1 & 13.2 & 12.1 & 40.4 \\
\hline Colombia $(1985)^{\mathrm{b}}$ & 5.5 & 5.4 & 34.4 & 7.8 & 7.0 & 26.9 \\
\hline Ecuador (1990) & 3.5 & 5.0 & 40.6 & 3.0 & 3.9 & 29.3 \\
\hline Guatemala (1989) & 29.2 & 38.9 & 74.9 & 16.9 & 20.3 & 64.6 \\
\hline Honduras (1988) & 18.7 & 21.8 & 66.3 & 23.1 & 24.0 & 61.1 \\
\hline México (1990) & 4.1 & 6.2 & 43.2 & 3.7 & 4.4 & 30.6 \\
\hline Nicaragua (1985) & 13.1 & 11.3 & 51.1 & 11.3 & 15.6 & 56.0 \\
\hline Panamá $(1990)^{c}$ & 3.9 & 4.2 & 26.3 & 2.7 & 3.0 & 25.3 \\
\hline Venezuela $(1990)^{d}$ & 2.1 & $\ldots$ & 46.0 & 3.2 & $\ldots$ & 35.1 \\
\hline
\end{tabular}

Fuente: Según datos de los censos de: Bolivia, INE (1989), Encuesta nacional de población y vivienda, 1988. Resultados finales; Brasil, IBGE (1989), Anuario estadístico do Brasil; Colombia, DANE (1986), Censo 1985; Ecuador, INEC (1991), v Censo de población y IV de vivienda, 1990. Resultados definitivos. Resumen nacional; Guatemala, INE (1989), Encuesta nacional sociodemográfica; Honduras, Secretaría de Planificación, Coordinación y Presupuesto (1988), Censo nacional de población, tomo I; México, INEGI (1990), Resumen general. XI Censo general de población y vivienda; Nicaragua, INEC (1989), ESDENIC 85. Tabulaciones básicas, vol. I. Características generales de la población; Panamá, Dirección de Estadística y Censos (1990), Censos nacionales de población y vivienda. Resultados finales básicos; Venezuela, Oficina Central de Estadística e Informática de la Presidencia de la República (1990), Anuario estadístico.

${ }^{a}$ Los datos del grupo de edad mayor corresponden a población de 60 años y más.

${ }^{\mathrm{b}}$ En el caso de Colombia, los grupos de edad corresponden a los tramos 12 a 17 años, 18 a 24 años y 60 años y más.

" Los datos corresponden a las categorías "Sin grado de instrucción aprobado" de los censos de 1990.

d Por falta de disponibilidad de los datos las cifras del grupo de edad de 15 a 19 años corresponden al tramo de 15 a 24 años. 
Por un lado, el analfabetismo es el mayor factor de aislamiento de las mujeres indígenas, ya que las aparta de la cultura nacional y contribuye a mantenerlas en situación de pobreza extrema. Por otro, es debido a su baja integración a la sociedad latinoamericana y a su ausencia del sistema educativo que ellas han podido preservar, en parte, su tradición. El dilema en que se encuentran estas mujeres se ve reforzado por las tradiciones indígenas mismas, según las cuales la protección de la cultura pertenece al ámbito del poder y de las responsabilidades femeninas (D'Emilio, 1989).

Aunque es todavía demasiado temprano para juzgar sus efectos reales, en casi todos los países con significativos porcentajes de población indígena está en marcha un proceso de institucionalización de la educación bilingüe intercultural para enfrentar la situación. Existe un mayor nivel de conciencia acerca de la compleja y heterogénea realidad lingüística y cultural, sobre la importancia de la lengua y cultura maternas como instrumentos del progreso educativo y sobre la necesidad de rescatar las poblaciones indígenas de la condición de marginalidad en que se encuentran.

Sin embargo, a pesar de estos esfuerzos se observa que, al encontrarse la mayoría de las poblaciones indígenas en el medio rural, las niñas y los niños indígenas en general carecen de escuelas completas, de maestros y maestras capacitados en educación bilingüe intercultural, de libros de texto bilingües y de recursos en general. Tampoco facilita la integración de las niñas el papel tradicional de las mujeres en el campo y el hecho de que su socialización dentro del trabajo se inicia tempranamente: en este contexto, su asistencia regular a la escuela encuentra resistencia de parte de los padres porque las aleja de tal proceso y hace que dejen de "contribuir con su trabajo a la producción agrícola y función reproductora de su madre" (Zúñiga, 1989).

\section{b) Situación educacional de las mujeres negras}

Es necesario distinguir entre la situación de los países con mayoría negra, como los del Caribe, y la de aquellos en donde las mujeres negras son parte de las minorías nacionales. La situación de las mujeres caribeñas destaca en la región por la importancia de su participación en su sociedad - reconocida en muchos de los estudios antropológicos realizados en el Caribe (Rivera, 1993) - y por su integración positiva al sistema de educación formal. En 1990, con la excepción de Haití, cuya tasa de analfabetismo femenino $(52.6 \%)$ sólo era superada en la región por la de
$52.9 \%$ en Guatemala (cuadro 3), la mayoría de los países del Caribe exhibían tasas de escolarización de las mujeres cercanas o superiores al promedio regional (cuadro 4$)^{2}$, que en muchos casos superaban las tasas masculinas en la enseñanza media y superior (CEPAL, 1991a; Naciones Unidas, 1992).

Según las informaciones recogidas en el I Encuentro de Mujeres Negras Latinoamericanas y del Caribe, que se celebró en julio de 1992 en la República Dominicana y donde se reunieron más de 300 representantes de 32 países (León, 1992), en los otros países de la región el acceso de las mujeres negras a la educación formal es limitado a la vez por razones de discriminación étnica y por sus condiciones socioeconómicas. Esto último porque en estos países la población negra se concentra en los sectores de menores recursos y con menos acceso a los servicios e instancias de poder. Así, los datos presentados en dicho Encuentro destacan que, por ejemplo, las mujeres haitianas que viven en los bateyes de la República Dominicana no tienen acceso a la educación porque "no existen escuelas ni recursos para solventarlas"; en Honduras el $48.3 \%$ de la población de mujeres negras no ha terminado sus estudios primarios; en Uruguay, sus "niveles educacionales son bajos y $75 \%$ de la inserción laboral se produce en el servicio doméstico", y en Brasil sólo $11 \%$ de ellas llega a los niveles de enseñanza media (León, 1992).

Lo anterior corrobora las conclusiones de un estudio de la Fundación Carlos Chagas sobre raza y oportunidades educacionales en Brasil, el cual señala que la proporción de niños negros y mulatos que nunca han tenido acceso al sistema escolar es tres veces mayor que la de niños blancos, y que una proporción más elevada de niños no blancos ingresa tardíamente en la escuela y acumula repeticiones y atrasos en su trayectoria escolar (Hasenbalg y Do Valle Silva, 1990). Vale subrayar que en el marco de esta situación de profunda desigualdad, los niveles de estudios de las mujeres brasileñas no blancas son levemente superiores a los de sus pares varones. ${ }^{3}$

\footnotetext{
2 En 1988, según datos de la UNESCO y del CELADE (CEPAL/ UNESCO-OREALC, 1992), la tasa neta de escolarización de la población de 6 a 11 años (educación primaria) era de $87.6 \%$; la de la población de 12 a 17 años (educación media) de $71.6 \%$; y la de la población de 18 a 23 años (educación superior) de $27.2 \%$.

3 Según los datos de la encuesta nacional de hogares de 1982 en Brasil, la última que procesó datos desagregados por raza y sexo, la tasa de analfabetismo de las mujeres negras y mulatas era de $38.3 \%$. frente a $39.4 \%$ para los varones; $55.5 \%$ de ellas había terminado la educación primaria (55.2\% de los hombres) y $6.2 \%$ la educación secundaria (5.4\% de los hombres) (Valdés y Gomariz, 1992).
} 


\begin{tabular}{|c|c|c|c|c|c|}
\hline \multirow[b]{3}{*}{ Países } & \multicolumn{5}{|c|}{$\begin{array}{l}\text { América Latina y el Caribe (22 países): Tasas de analfabetismo y número } \\
\text { de analfabetos, por sexo, } 1990^{\mathrm{a}} \\
\text { (Porcentajes y miles) }\end{array}$} \\
\hline & \multicolumn{3}{|c|}{ Tasas de analfabetismo (\%) } & \multicolumn{2}{|c|}{$N^{0}$ de analfabetos } \\
\hline & Total & Mujeres & Hombres & $\begin{array}{l}\text { Miles } \\
(1990)\end{array}$ & $\begin{array}{c}\text { Variación } \\
(\%) \\
1970-1990\end{array}$ \\
\hline Argentina & 4.7 & 4.9 & 4.5 & 1065 & -12.6 \\
\hline Bolivia & 22.5 & 29.3 & 15.3 & 923 & -16.5 \\
\hline Brasil & 18.9 & 20.2 & 17.5 & 18407 & 6.6 \\
\hline Colombia & 13.3 & 14.1 & 12.5 & 2702 & 2.5 \\
\hline Costa Rica & 7.2 & 6.9 & 7.4 & 139 & 15.8 \\
\hline Cuba & 6.0 & 7.0 & 5.0 & 484 & -36.3 \\
\hline Chile & 6.6 & 6.8 & 6.5 & 603 & -15.3 \\
\hline Ecuador & 14.2 & 16.2 & 12.2 & 909 & 0.3 \\
\hline El Salvador & 27.0 & 30.0 & 23.8 & 787 & -6.4 \\
\hline Guatemala & 44.9 & 52.9 & 36.9 & 2253 & 39.3 \\
\hline Guyana & 3.6 & 4.6 & 2.5 & 25 & -34.7 \\
\hline Haití & 47.0 & 52.6 & 40.9 & 1858 & -9.9 \\
\hline Honduras & 26.9 & 29.4 & 24.5 & 766 & 16.6 \\
\hline Jamaica & 1.6 & 1.4 & 1.8 & 26 & -31.6 \\
\hline México & 12.7 & 14.9 & 10.5 & 7066 & 2.2 \\
\hline Panamá & 11.9 & 11.8 & 11.9 & 187 & 6.8 \\
\hline Paraguay & 9.9 & 11.9 & 7.9 & 252 & 4.3 \\
\hline Perú & 14.9 & 21.3 & 8.5 & 2025 & -8.0 \\
\hline Rep. Dominicana & 16.7 & 18.2 & 15.2 & 744 & 0.1 \\
\hline Suriname & 5.1 & 5.3 & 4.9 & 13 & -45.3 \\
\hline Uruguay & 3.8 & 4.1 & 3.4 & 88 & -43.0 \\
\hline Venezuela & 11.9 & 10.4 & 13.3 & 1450 & 0.3 \\
\hline
\end{tabular}

Fuentes: UNESCO, Informe mundial sobre la educación 1991, París.

a Sobre la población de 15 años y más.

Aún en los países de la región donde es positiva la proporción mujeres/hombres en el acceso a los sistemas de educación de la población negra, las mujeres reunidas en el Encuentro de 1992 denunciaron los contenidos racistas de la enseñanza -además de la discriminación de género ya presente- en los cuales se niega su identidad étnica y cultural, lo que les impide un real acceso a una educación equitativa.
Este sesgo está reforzado por las imágenes estereotipadas que transmiten los medios de comunicación y que asocian las mujeres negras "a papeles casi exclusivamente serviles o sexuales". Así, tanto como las mujeres indígenas, las mujeres negras "enfrentan tres niveles de opresión: la pobreza, la negritud y el género" (León, 1992), cuyos efectos están presentes en su proceso educativo. 
CUADRO 4

América Latina y el Caribe (24 paises): Matrícula regional, por grupos de edades y por sexo, 1990

\begin{tabular}{|c|c|c|c|c|c|c|c|c|c|}
\hline \multirow[b]{2}{*}{ Países } & \multicolumn{3}{|c|}{6 a 11 años } & \multicolumn{3}{|c|}{12 a 17 años } & \multicolumn{3}{|c|}{18 a 23 años } \\
\hline & Total & Mujeres & Hombres & Total & Mujeres & Hombres & Total & Mujeres & Hombres \\
\hline Argentina & 97.2 & 97.0 & 97.3 & 79.4 & 82.5 & 76.4 & 56.9 & 61.5 & 52.3 \\
\hline Barbados & $\ldots$ & $\ldots$ & $\ldots$ & 89.4 & 87.9 & 90.8 & 28.4 & 27.4 & 28.8 \\
\hline Bolivia & 87.9 & 85.7 & 90.1 & 54.2 & 48.3 & 60.1 & 27.8 & 21.3 & 34.5 \\
\hline Brasil & 77.9 & 75.8 & 79.9 & 74.9 & 72.6 & 77.1 & 22.8 & 24.9 & 20.6 \\
\hline Colombia & 80.4 & 81.6 & 79.2 & 71.1 & 71.9 & 70.3 & 26.2 & 24.1 & 28.3 \\
\hline Costa Rica & 87.1 & 87.6 & 86.7 & 47.7 & 47.7 & 47.8 & 20.5 & 18.4 & 22.6 \\
\hline Cuba & 97.4 & 97.3 & 97.6 & 80.2 & 80.8 & 79.7 & 38.0 & 40.8 & 35.3 \\
\hline Chile & 90.5 & 89.5 & 91.5 & 91.2 & 90.8 & 91.7 & 29.0 & 27.7 & 30.2 \\
\hline Ecuador & 92.2 & 92.8 & 91.5 & 75.5 & 73.9 & 77.0 & 48.7 & 47.6 & 49.7 \\
\hline El Salvador & 70.8 & 72.0 & 69.7 & 53.8 & 55.0 & 52.6 & 21.2 & 21.8 & 20.5 \\
\hline Guatemala & 56.9 & 54.3 & 59.3 & 43.4 & 38.9 & 47.6 & 15.3 & 10.3 & 20.1 \\
\hline Guyana & 86.1 & 85.0 & 87.2 & 54.2 & 55.9 & 52.4 & 7.0 & 7.1 & 6.9 \\
\hline Haití & 59.7 & 58.7 & 60.7 & 55.0 & 52.3 & 57.8 & 13.7 & 12.4 & 14.9 \\
\hline Honduras & 82.3 & 83.7 & 80.9 & 55.2 & 57.2 & 53.2 & 21.3 & 23.4 & 19.2 \\
\hline Jamaica & 100,0 & 100.0 & 100.0 & 82.7 & 83.3 & 82.2 & 7.2 & 7.0 & 7.4 \\
\hline México & 100.0 & 100.0 & 100.0 & 68.1 & 66.3 & 69.9 & 23,4 & 20.0 & 26.8 \\
\hline Nicaragua & 72.0 & 74.2 & 69.8 & 51.8 & 60.8 & 43.0 & 27.8 & 36.7 & 19.0 \\
\hline Panamá & 91.6 & 91.4 & 91.8 & 66.3 & 66.3 & 66.4 & 35.4 & 38.9 & 32.1 \\
\hline Paraguay & 80.1 & 80.4 & 79.8 & 50.2 & 47.3 & 53.0 & 15.3 & 14.3 & 16.2 \\
\hline Perú & 98.9 & 97.5 & 100.0 & 81.0 & 78.3 & 83.6 & 31.6 & 25.5 & 37.6 \\
\hline Suriname & 99.4 & 99.0 & 99.7 & 93.9 & 93.9 & 93.9 & 14.2 & 14.1 & 14.3 \\
\hline Trinidad y Tabago & 100.0 & 100.0 & 100.0 & 63.8 & 65.2 & 62.5 & 5.3 & 5.1 & 5.6 \\
\hline Uruguay & 94.6 & 93.7 & 95.5 & 80.0 & 81.9 & 78.2 & 61.6 & 65.6 & 57.7 \\
\hline Venezuela & 91.0 & 91.3 & 90.7 & 64.8 & 68.6 & 61.1 & 26.4 & 27.6 & 25.2 \\
\hline
\end{tabular}

Fuente: Estimaciones de la UNESCO recogidas en CEPAL, $1994 \mathrm{~b}$.

\section{Analfabetismo}

A pesar de los importantes avances de la alfabetización, en la región persisten diferencias agudas en los niveles alcanzados por los distintos países, y grandes variaciones dentro de éstos entre las mujeres de diversas categorías socioocupacionales (Schiefelbein y Peruzzi, 1991). Así, a nivel regional se notan disparidades que van desde una tasa de analfabetismo absoluto femenino de $1.4 \%$ en Jamaica hasta una de $52.9 \%$ en Guatemala (cuadro 3). A nivel nacional se observa que, por ejemplo, las tasas de analfabetismo femenino du- plican las masculinas en las zonas urbanas de Bolivia, Guatemala y Haití, y son cercanas o muy superiores al doble en las zonas rurales (en su mayoría con poblaciones indígenas) de Bolivia, Guatemala, México y Perú (cuadro 1). Además de los efectos anteriormente señalados de la brecha generacional sobre las tasas de analfabetismo, la particular situación de estos países corrobora que el analfabetismo femenino tiende a presentarse en mayor grado en las mujeres de estrato bajo, tanto en áreas urbanas como rurales (Letelier Gálvez, 1993).

Es vital insistir en las graves consecuencias del analfabetismo sobre la situación de las mujeres en su 
sociedad, no solamente porque les impide participar como ciudadanas activas en su grupo y comunidad - lo que las margina del acceso a los proyectos de desarrollo y resta capacidad a las mujeres beneficia- rias para aprovecharlos-, sino también porque la imposibilidad de leer las leyes y de conocer sus derechos las mantienen "entrampadas en los cánones sexistas" de la cultura latinoamericana (Braslavsky, 1984).

\section{III}

\section{Los avances en la cobertura educativa}

A pesar de los problemas estructurales que afectan a los procesos de educación en América Latina y el Caribe, la situación educativa de las mujeres mejoró de manera importante en las últimas décadas, tanto por la mejoría general del nivel educativo como por el aumento de la matrícula femenina en relación con la de los varones. Ya los censos de población de los años ochenta muestran "no sólo la desaparición de las grandes diferencias en los niveles de escolaridad por sexo que se observaban en los años 50 , sino que la situación se revierte en la mitad de los países donde las mujeres han logrado ventajas en el acceso a la primaria y secundaria" (Schiefelbein y Peruzzi, 1991). En la actualidad, las mujeres han alcanzado en la mayoría de los países de la región una posición paritaria en los niveles básico y medio, y en varios países están superando las tasas de escolarización masculina en la educación superior (Valdés y Gomariz, 1992 y 1993; Naciones Unidas, 1992; CEPAL, 1994b).

\section{Educación preescolar}

Según cifras de la uNESCO (1992b) y de FLACSO (Valdés y Gomariz, 1992 y 1993), en los años ochenta la educación preprimaria atendía de manera generalmente paritaria a niños y niñas, variando 1 o 2 puntos porcentuales en favor de unos u otras, según los países. Un estudio llevado a cabo en Chile a partir de las encuestas de hogares de 1990 comprueba que "en este nivel no se aprecian diferencias por género, pero sí por ingreso, siendo mayor la participación a medida que se sube en la distribución por quintiles" (UNICEF/Chile, MIDEPLAN, 1993). De hecho, el sector privado ha tenido un papel importante en la atención a los sectores que pueden financiar el servicio de educación preescolar, lo que ha limitado notablemente su contribución en las zonas rurales. Así, la oferta de educación preprimaria favorece a los sectores medios y altos de la población, pese a ciertos avances en áreas marginales mediante programas no formales.

En la propuesta de mejoramiento de los sistemas educativos de la región, planteada por la CEPAL y la UNESCO, se hace hincapié en la educación preescolar como medio para resolver muchos problemas en el proceso educativo posterior de los niños (CEPAL/UNESCOOREALC, 1992). Dada la importancia de sostener la igualdad de partida entre mujeres y varones en el sistema de educación formal, cabe esperar que esa enseñanza sea estimulada por los gobiernos y extendida a todos los sectores sociales a la hora de buscar medidas para consolidar la cobertura educacional en sus países.

\section{Educación primaria}

En cuanto a la situación de las mujeres en la educación primaria, según datos adelantados por las Naciones Unidas (División para el Adelanto de la Mujer), en 1990 la matrícula de mujeres en la región era de 96 por cada 100 hombres, un promedio equivalente al de los países de Europa occidental y oriental, que hasta ahora no ha sido superado en región alguna del mundo. ${ }^{4} \mathrm{~A}$ nivel nacional, esto representa tasas de matrícula en el primer grado que van desde el $54.3 \%$ de las mujeres de 6 a 11 años (90 por cada 100 hombres) en Guatemala hasta $100 \%$ en Jamaica, México y Trinidad y Tabago.

Los problemas que todavía existen para completar la universalización de la educación primaria afectan a las niñas y a los niños por igual. En los estudios de la UNESCO se mencionan como principales la dificultad de atender a los niños y niñas que viven en la calle o en zonas aisladas (entre 3 y $15 \%$ en la mayoría de los países de la región); la ausencia de una oferta de educación bilingüe intercultural a

4 Según cálculos de la propia División, a partir de los cuadros 2.3, 2.4 y 2.5 de la tercera versión de la base de datos WISTAT (Indicadores y estadísticas sobre la mujer), de las Naciones Unidas. 
nivel de enseñanza primaria en las zonas de alta concentración indígena; el ingreso tardío, que afecta particularmente a los alumnos de familias de menores niveles socioeconómicos; la fuerte deserción temporal en el momento de las cosechas en las zonas rurales, y la alta tasa de repetición que resulta tanto de los problemas anteriores como de la poca calidad de la enseñanza y la falta de adecuación del currículo a la realidad de los alumnos y alumnas (UNESCO, 1992a).

Aunque pueden exhibir tasas importantes de repitencia y de abandono en las áreas marginales urbanas y rurales, las mujeres muestran un rendimiento escolar mayor que los hombres en todos los países donde se puede obtener cifras desagregadas por sexo (Valdés y Gomariz, 1992 y 1993). Sin embargo, la incompatibilidad de los datos disponibles no permite establecer tasas regionales ciertas. Según la información de CEPAL/UNESCO (1992), la tasa de repetición es de menos de $10 \%$ solamente en cinco países, mientras sólo en otros tres el $80 \%$ de los alumnos logra terminar su educación primaria.

\section{Educaclón secundaria}

Las mujeres han aprovechado ampliamente la expansión de la educación media en la región, no solamente alcanzando un nivel de matrícula similar al de los varones, sino superándolo en 11 países de América Latina y varios del Caribe, y llegando a un promedio regional de 109 mujeres por cada 100 hombres (cuadro 4). Cabe señalar que aún cuando la cobertura disminuye de manera muy significativa para ambos sexos en las zonas rurales, la relación entre las tasas de integración a la educación secundaria de hombres y mujeres sigue siendo la misma (cuadro 5). Es decir, fuera de las poblaciones indígenas -que viven un problema de exclusión aún más complejo-, en la enseñanza media las mujeres mantienen sus avances en términos relativos, a pesar de los problemas estructurales de la educación en los distintos países. No obstante, se debe hacer una salvedad: la matrícula femenina en la educación media técnica, especialmente en el área industrial, sigue baja "aun en aquellos países que han abierto esa educación a las mujeres" (Schiefelbein y Peruzzi, 1991).

CUADRO 5

América Latina (12 países): Niveles de estudio de la población en las zonas rurales, por sexo

\begin{tabular}{|c|c|c|c|c|c|c|c|c|}
\hline \multirow[b]{2}{*}{ País } & \multicolumn{2}{|c|}{$\begin{array}{l}\text { Ninguno o } \\
\text { menos de } 1 \text { año }\end{array}$} & \multicolumn{2}{|c|}{$\begin{array}{c}\text { Nivel } \\
\text { primario }\end{array}$} & \multicolumn{2}{|c|}{$\begin{array}{c}\text { Nivel } \\
\text { secundario }\end{array}$} & \multicolumn{2}{|c|}{$\begin{array}{c}\text { Nivel } \\
\text { superior }\end{array}$} \\
\hline & Mujeres & Hombres & Mujeres & Hombres & Mujeres & Hombres & Mujeres & Hombres \\
\hline Bolivia (1992) & 40.0 & 18.1 & 44.7 & 61.4 & 5.4 & 12.2 & 0.3 & 0.8 \\
\hline Brasil (1988) & 32.6 & 37.7 & 55.0 & 52.6 & 9.7 & 7.1 & 2.5 & 2.5 \\
\hline Colombia (1985) & 21.3 & 21.1 & 62.8 & 64.1 & 11.9 & 10.7 & 0.4 & 0.5 \\
\hline Costa Rica (1992) & 7.9 & 8.2 & 66.4 & 67.3 & 21.7 & 20.2 & 3.5 & 3.5 \\
\hline Cuba (1981) & 5.9 & 5.1 & 67.5 & 61.2 & 25.9 & 32.8 & 0.7 & 1.0 \\
\hline Chile (1989) & 0.6 & 0.8 & 63.5 & 66.6 & 17.0 & 14.8 & 0.9 & 1.1 \\
\hline Ecuador (1990) & 24.0 & 16.2 & 51.2 & 56.2 & 15.0 & 17.2 & 2.9 & 3.6 \\
\hline Paraguay (1982) & 18.7 & 11.4 & 71.7 & 76.7 & 6.4 & 9.3 & 1.0 & 0.8 \\
\hline Perú (1991-1992) & 21.8 & 8.3 & 60.9 & 64.5 & 14.4 & 23.3 & 2.4 & 3.2 \\
\hline República Dominicana (1991) & 29.8 & 29.4 & 57.4 & 56.4 & 10.7 & 11.9 & 1.5 & 2.1 \\
\hline Uruguay (1985) & 7.6 & 9.0 & 70.6 & 72.5 & 19.6 & 16.2 & 0.9 & 1.0 \\
\hline Venezuela (1981) & 37.9 & 25.2 & 54.4 & 67.9 & 7.5 & 6.5 & 0.3 & 0.4 \\
\hline
\end{tabular}

Fuente: Valdés y Gomariz (1992 y 1993). 
Si bien el rendimiento escolar -evaluado en términos de abandono de los estudios, repetición, aplazamientos y sobreedad - es menor en la enseñanza secundaria, las mujeres siguen mostrando una eficacia mayor que los hombres en todos los países para los cuales se dispone de información desagregada por sexo, con independencia del nivel socioeconómico o del área de residencia (Valdés y Gomariz, 1992 y 1993). Cabe señalar que en los casos de deserción femenina parecen predominar las razones económicas y de embarazo precoz. Sin embargo, en parte por la falta de datos desagregados por sexo, se desconoce el número de mujeres jóvenes que han desertado del sistema escolar formal en América Latina y el Caribe. Por otra parte, debe considerarse también que los efectos del profundo deterioro de la situación social en la región han tenido "numerosas manifestaciones, tales como el aumento del porcentaje de jóvenes que no estudian ni trabajan" (CEPAL, 1994a).

\section{Educación superior}

Aunque su expansión ha sido más restringida que la de los niveles educativos anteriores, la educación superior también hace considerables y rápidos avances en la región, ${ }^{5}$ los que son compartidos por las mujeres de manera muy desigual según los países.

Así, detrás de la tasa regional de 106 mujeres por 100 varones matriculados en la educación superior establecida por las Naciones Unidas para 1990 -la proporción más alta a nivel mundial-, se disimulan discrepancias que van desde proporciones de 50 mujeres por cada 100 varones en Guatemala, a otras de 200 mujeres y más en países pequeños del Caribe (Naciones Unidas, 1992; CEPAL, 1994b). Estas diferencias se hacen aún más marcadas cuando están cruzadas con disparidades de un país a otro en el nivel de estudios superiores alcanzado por la población, y diferencias entre las zonas urbanas y rurales dentro de los países (cuadro 6).

5 Las tasas de escolarización brutas en el tercer nivel subieron de un promedio de $3 \%$ en 1960 a $19 \%$ en 1990 .

América Latina (12 paises): Niveles de estudio de la población en cada país, en zonas urbanas y rurales ${ }^{a}$

\begin{tabular}{|c|c|c|c|c|c|c|c|c|}
\hline & \multicolumn{2}{|c|}{$\begin{array}{l}\text { Ninguno o } \\
\text { menos de } 1 \text { año }\end{array}$} & \multicolumn{2}{|c|}{$\begin{array}{c}\text { Nivel } \\
\text { primario }\end{array}$} & \multicolumn{2}{|c|}{$\begin{array}{c}\text { Nivel } \\
\text { secundario }\end{array}$} & \multicolumn{2}{|c|}{$\begin{array}{c}\text { Nivel } \\
\text { superior }\end{array}$} \\
\hline & $\mathrm{U}$ & $\mathbf{R}$ & U & $\mathbf{R}$ & $\mathrm{U}$ & $\mathbf{R}$ & $\mathbf{U}$ & $\mathrm{R}$ \\
\hline Bolivia (1992) & 17.4 & 29.0 & 43.4 & 53.1 & 24.6 & 8.9 & 6.7 & 0.5 \\
\hline Brasil (1988) & 12.3 & 35.1 & 66.9 & 53.7 & 13.3 & 8.5 & 7.4 & 2.5 \\
\hline Colombia (1985) & 7.2 & 21.2 & 42.5 & 63.5 & 41.2 & 11.3 & 7.6 & 0.4 \\
\hline Costa Rica (1992) & 5.8 & 8.1 & 55.0 & 66.8 & 29.1 & 20.9 & 9.3 & 3.5 \\
\hline Cuba (1981) & 3.5 & 5.6 & 43.3 & 64.0 & 47.6 & 29.6 & 5.6 & 0.8 \\
\hline Chile (1989) & 0.5 & 0.7 & 41.8 & 65.2 & 41.6 & 15.8 & 7.9 & 1.1 \\
\hline Ecuador (1990) & 5.3 & 20.0 & 31.5 & 53.7 & 41.3 & 16.1 & 17.7 & 3.2 \\
\hline Paraguay (1982) & 10.6 & 14.9 & 63.5 & 74.3 & 18.2 & 7.9 & 5.6 & 0.9 \\
\hline Perú (1991-1992) & 6.8 & 15.0 & 42.8 & 62.7 & 33.3 & 18.9 & 16.7 & 2.8 \\
\hline República Dominicana (1991) & 17.5 & 29.6 & 49.5 & 57.0 & 22.9 & 11.3 & 10.0 & 2.1 \\
\hline Uruguay (1985) & 5.0 & 8.5 & 51.9 & 71.8 & 37.3 & 17.5 & 5.0 & 1.0 \\
\hline Venezuela (1981) & 15.1 & 31.1 & 56.8 & 61.6 & 23.4 & 7.0 & 4.7 & 0.3 \\
\hline
\end{tabular}

Fuente: Valdés y Gomariz (1992 y 1993).

a Brasil: Población urbana/región sudeste; población rural/región nordeste; Bolivia, Costa Rica, Chile, Paraguay, Perú, República Dominicana, Uruguay y Venezuela: población urbana de todo el país. 
En cuanto a la elección de carrera universitaria, ha aumentado la proporción de mujeres presentes en carreras tradicionalmente consideradas como masculinas, sobre todo en los países con deficiencias educativas graves (Valdés y Gomariz, 1992 y 1993). Sin embargo, el cambio aún no es suficiente para eliminar la segmentación que enfrentan las mujeres en sus elecciones vocacionales. La dificultad reside en que de hecho se trata de discriminación de género, siendo la situación muy parecida a la de los países industrializados, donde una gran proporción de las mujeres "se concentra en carreras cuyo ejercicio permite ho- rarios más flexibles o es más compatible con una mayor dedicación a las tareas del hogar, y donde existe un menor riesgo de discriminación en los salarios según el sexo" (CEPAL/UNESCO-OREALC, 1992). Así, el origen de la discriminación no es tanto que el sistema educativo establezca diferencias con el propósito de desventajar abiertamente a las mujeres, sino que dicho sistema "forma parte de una sociedad más amplia y, por lo tanto, las oportunidades que él ofrece son utilizadas en forma diferencial por mujeres y hombres según las valoraciones y creencias dominantes" en esa sociedad (Varela, 1991).

\section{IV}

\section{Obstáculos socioculturales que enfrentan} las mujeres en el sistema educativo

Estos rasgos sexistas tienen que ver con la propensión del pensamiento occidental a dividir y clasificar en género a personas, capacidades y actividades, en una actitud que "disminuye, excluye, subrepresenta y estereotipa a las personas de acuerdo con su sexo" (Abu Nasr, Lorfing y Mikati, 1983, citado por Michel, 1989). De ello fluye la sobrevaloración de lo masculino y el silenciamiento de lo femenino en la cultura académica, lo que luego reaparece en los contenidos estereotipados de la enseñanza, en la falta de atención que reciben las alumnas en las aulas de clases y en oportunidades vocacionales truncadas para las mujeres. Veremos a continuación cómo los estereotipos sexuales, la actitud de los docentes y la segregación de género en la orientación hacia el mercado laboral pueden contribuir a mutilar las posibilidades personales de las niñas y obligarlas "a interiorizar su puesto secundario en la sociedad" (Subirats, 1990).

\section{Estereotipos sexuales en la enseñanza}

Un examen atento de los estudios que se han hecho en la región sobre los contenidos del material educativo - libros de textos, ilustraciones, películas- utilizado en la educación básica y media en la gran mayoría de los países de América Latina y el Caribe confirma la presencia de discriminación por género. El análisis que apunta a este tipo de discriminación se hace a partir de indicadores de sexismo tales como la frecuencia de la presencia de los personajes de sexo femenino y masculino, su participación en las actividades laborales y en las actividades domésticas y familiares, los adjetivos calificativos utilizados para referirse a uno y otro sexo, así como las situaciones de protagonismo (Chile, SERNAM, 1992). El examen de textos escolares de Belize (Laaksonen, 1991), Chile (Chile, SERNAM, 1992), Costa Rica (Costa Rica, Ministerio de Cultura, Juventud y Deportes/Ministerio de Educación Pública, 1991), El Salvador, Guatemala y Panamá (Caldera, 1990), Perú (Valdés y Gomariz, 1993) y Uruguay (Piotti Nuñez, 1990; Valdés y Gomariz, 1992) indica que los libros y textos revisados se refieren a las mujeres en menos del $30 \%$ de los casos de protagonismo, y que las presentan en situación de inferioridad social, debilidad o subordinación (Caldera, 1990). En Venezuela, el análisis de los estereotipos sexuales en los textos escolares de educación preescolar y básica llevó a clasificar los estereotipos en tres categorías: la exageración de las características conductuales, los roles familiares o profesionales y las relaciones grupales. Como resultado, se destacó una clara incongruencia entre la realidad de la sociedad venezolana y los modelos presentados, los cuales correspondían "a la concreción de hechos sociales pasados" (Montero, 1993).

Esta discrepancia entre realidad y modelos caracteriza precisamente lo que son los estereotipos, es decir "modelos rígidos y anónimos a partir de los cuales son reproducidos, de manera automática, imágenes y comportamientos" (Dunningan, citado por 
Michel, 1989). Esto puede estar expresado de manera abierta, como en el caso de los currículos escolares que orientan a los niños y las niñas hacia disciplinas típicamente "masculinas" o "femeninas", o de manera latente, como en el caso de la omisión de ciertas cualidades o papeles como opciones válidas para las niñas o los niños (Michel, 1989). Así por ejemplo, los textos escolares de los distintos países de la región presentan principalmente a las mujeres en sus versiones idealizadas de madres y amas de casa (Piotti Núñez, 1990; Torres, 1993) e "inducen a pensar que los hombres ocupan los roles importantes en la vida nacional, tanto en el espacio privado como en el público. Cuando las mujeres aparecen actuando en espacios públicos, lo hacen regularmente en actividades consideradas tradicionalmente femeninas. Las acciones dinámicas, que exigen eficacia y productividad, o relacionadas con funciones de dirección o liderazgo, se atribuyen casi exclusivamente a los varones" (Valdés y Gomariz, 1992). En suma, tales estereotipos perjudican la autopercepción y la identidad de las niñas, y perpetúan los fundamentos de la discriminación de género (Rico, 1994).

Luego de los estudios sobre los contenidos de los materiales de enseñanza en los países mencionados, varios gobiernos han comenzado a modificar los textos escolares y presentar modelos femeninos que correspondan mejor a la realidad de las mujeres de la región. Como resultado se está incrementando levemente el número de imágenes que representan a las mujeres, aunque éstas siguen siendo una minoría. Se empieza también a flexibilizar la ilustración de los roles tradicionales y las mujeres pueden aparecer más activas fuera del ámbito privado y los hombres participar en las tareas domésticas y el cuidado de los niños. Sin embargo, no se ha logrado todavía reformular los currículos de manera que se valoren los aportes de ambos sexos y se muestre una imagen equilibrada de ambos.

Los obstáculos para traducir en material didáctico cambios socioculturales aún no completados por la sociedad son por cierto importantes, y no deben sorprender las dificultades que encuentran las autoridades educativas para producir textos adaptados a los nuevos tiempos. En la actualidad, esto desemboca en contenidos ambiguos que superponen modelos contradictorios y no preparan a los educandos para una visión clara de su proyecto de vida. En vez de los antiguos estereotipos, se acumulan "modelos, comportamientos y actitudes que no necesariamente significan ampliación de opciones y de nuevos horizontes, debido a que asumir prioritariamente los roles de la reproducción en un proyecto de familia parece ser aún inevitable. En forma paralela los modelos masculinos se modifican con más lentitud, lo cual sitúa las innovaciones en un proceso desequilibrado de transformación de las imágenes genéricas" (Rico, 1994).

Una forma de enfrentar el problema que despierta mucho interés en la región es la integración de lo femenino y de la perspectiva de género en la enseñanza de la historia en todos los niveles de los sistemas de educación formal. La incorporación de la historia de las mujeres a la cultura académica confirmaría su protagonismo en la sociedad, contribuyendo al desarrollo de la identidad y de la autovaloración de las niñas. Fomentar de tal manera una visión más compleja y moderna de la historia implica también democratizar el sistema educativo e introducir estudios sobre las culturas negra e indígena (León, 1992). Para hacerlo se necesitará una labor de investigación histórica y la colaboración tanto de las autoridades educativas como de las instituciones académicas. El reto es la construcción de un proyecto común de sociedad, abierto a la participación de las ciudadanas y de los ciudadanos, en el cual podrían caber las diferencias y las diversas identidades.

\section{Papel de los docentes}

En la democratización de los sistemas de educación formal, el papel de los docentes es otro factor fundamental, ya que entre el alumno o alumna y su profesor(a) se establece una relación de poder que es a la vez pedagógica, social, de comunicación y de transmisión de conocimientos y saberes, la que constituye el factor más determinante del aprendizaje escolar (Labourdette, 1989). Por estas mismas razones, los docentes "pueden cumplir un papel muy importante en la reproducción de prejuicios y estereotipos sexistas, o por el contrario pueden contribuir a su superación y eliminación" (Rico, 1994).

Gracias al aporte de los estudios sobre la presencia de la discriminación de género en los sistemas educativos, en la región se aprecia cada vez más la importancia de la relación entre los docentes y sus alumnos y alumnas en la transmisión de los estereotipos sexuales. Después de la familia, se comprueba que es en las aulas de clases donde las niñas y los niños tienen la experiencia de la jerarquización de los roles sociales y de los modelos que les va a imponer la sociedad en términos de actitudes y comportamiento. En este sentido, la forma en la cual 
los profesores apoyen, estimulen o ignoren las demandas de atención de las niñas y de los niños les informa de manera implícita sobre las normas de la sociedad que les rodea y los prepara para adaptarse a ellas. Por ejemplo, en un estudio llevado a cabo en Chile se ha demostrado que los profesores y profesoras prestan más atención a los niños en clase, tanto para revisar su trabajo escolar e interrogarlos como para disciplinarlos. Así, por tener un mayor rendimiento escolar y comportamientos más conformes a las reglas institucionales, las niñas son percibidas por su profesores como menos creativas y capaces de liderazgo que los varones (Rossetti, 1988 y 1992). Otro estudio realizado en Ecuador con docentes de ambos sexos encontró que $72 \%$ de ellos descalificaban las posibilidades de las mujeres en las materias relacionadas con la técnica y que tres de cada diez se sentían en la obligación de orientar a los alumnos hacia "carreras propias de su sexo" (Robalino, Villanueva e Isch, citado en Rico, 1994).

Capacitar a los docentes, mujeres y hombres, con el propósito de sensibilizarlos a las consecuencias de su comportamiento e incitarlos a transformar su aula en espacio para el aprendizaje de los cambios culturales que se dan fuera de ella, es aún más importante cuando se toma en cuenta que en los sistemas educativos de la región los profesores son en su mayoría mujeres. Según las cifras recogidas por la FLACSO a lo largo de la región para su compendio estadístico Mujeres latinoamericanas en cifras (Valdés y Gomariz, 1992 y 1993), en la gran mayoría de los países de la región son mujeres la casi totalidad de los docentes en el nivel preescolar, las tres cuartas partes en el nivel primario y la mitad en la enseñanza secundaria. En cambio, son minoría en la educación superior. ${ }^{6} \mathrm{La}$ sola excepción está constituida por los docentes de la enseñanza normal, en la cual predominan las mujeres tanto entre los profesores como entre los alumnos. Tampoco las mujeres están presentes en los puestos directivos o administrativos de importancia y son pocos los esfuerzos por capacitar a los docentes en la perspectiva de género, lo que tendería a perpetuar un círculo vicioso entre su propia situación y la reproducción del sesgo discriminatorio basado en el sexo dentro del proceso educativo.

Las repercusiones de este estado de hecho las expresaron las profesoras del Paraguay en julio de

$622.6 \%$ en Colombia; $34.2 \%$ en Costa Rica; $45.0 \%$ en Cuba; $17,8 \%$ en Ecuador; $19.0 \%$ en Guatemala; $33.9 \%$ en Panamá; $15.2 \%$ en Paraguay; $21.7 \%$ en Perú; $34.0 \%$ en Uruguay y $37.4 \%$ en Venezuela.
1991, cuando la Red de Educadores Populares organizó una campaña "Por una educación no sexista". En los seminarios realizados con docentes de escuelas públicas y privadas, las profesoras afirmaron de manera muy clara que "se estimaban poco valorizadas y no se consideraban agentes directos de la reforma educativa" (CEPAL, 1992).

\section{Segregación de género en la orientación vo- cacional}

Además de lo que se haga en el proceso educativo propiamente tal, para superar la discriminación de género en los sistemas de educación formal es preciso a la vez que se mire la educación desde la perspectiva del trabajo y de las demandas que surgen de los procesos productivos, y que se adopten medidas para corregir la desigualdad de oportunidades educativas para las mujeres debido al papel que se les asigna "en el desarrollo social como factores de reproducción de la vida más que actores sociales en pleno ejercicio de sus derechos" (Dasso y Montaño, citado en CEPAL, 1991b).

Dado el proceso de transformación productiva en curso en la región, con nuevas demandas en el mercado del trabajo, es necesario acrecentar de manera significativa la participación de las mujeres en el progreso científico y tecnológico y en la producción de conocimiento en general, lo cual influirá en la definición de la producción, la división del trabajo por sexo y los valores culturales que incorpora la sociedad; asimismo, se debería incrementar vigorosamente el esfuerzo de educación técnica en todos los países. Y en momentos en que la región plantea la urgencia de modernizar la enseñanza de los principios de gestión para adaptarlos a las necesidades de la empresa moderna, será también importante que las mujeres sean iniciadas en las nuevas formas de liderazgo, de gestión y de toma de decisiones.

En muchos países de la región, el avance educativo de las mujeres durante las últimas tres décadas ha permitido que la población económicamente activa femenina tenga hoy un nivel educacional más alto que la masculina (cuadro 7). Además, se estima que en la mayoría de los países de la región las mujeres acceden a los puestos calificados con un promedio de dos años de estudio más que el de los varones (CEPAL, 1991b; Psacharopoulos y Tzannatos, 1992). Sin embargo, aun cuando las mujeres constituyen alrededor del $50 \%$ de los alumnos matriculados en los establecimientos de educación secundaria y superior, 
CUADRO 7

América Latina (12 países): Población económicamente activa por sexos y según años de estudio

\begin{tabular}{|c|c|c|c|c|c|c|c|c|}
\hline \multirow[b]{2}{*}{ País } & \multicolumn{2}{|c|}{$\begin{array}{c}\text { Ninguno o } \\
\text { menos de } 1 \text { año }\end{array}$} & \multicolumn{2}{|c|}{$\begin{array}{c}\text { Enseñanza } \\
\text { primaria }\end{array}$} & \multicolumn{2}{|c|}{$\begin{array}{l}\text { Enseñanza } \\
\text { secundaria }\end{array}$} & \multicolumn{2}{|c|}{$\begin{array}{l}\text { Enseñanza } \\
\text { superior }\end{array}$} \\
\hline & Mujeres & Hombres & Mujeres & Hombres & Mujeres & Hombres & Mujeres & Hombres \\
\hline \multicolumn{9}{|l|}{ Brasil } \\
\hline 1988 & 14.1 & 18.8 & 56.5 & 61.3 & 29.1 & 19.7 & $\ldots$ & $\ldots$ \\
\hline \multicolumn{9}{|c|}{ Colombia } \\
\hline 1985 & 10.4 & 12.0 & 44.9 & 51.4 & 33.9 & 27.8 & 7.7 & 8.8 \\
\hline 1989 & 2.8 & 1.8 & 32.8 & 32.4 & 49.2 & 46.9 & 15.1 & 18.9 \\
\hline \multicolumn{9}{|c|}{ Costa Rica } \\
\hline 1990 & 3.1 & 5.4 & 43.3 & 57.3 & 34.5 & 26.6 & 18.0 & 9.7 \\
\hline \multicolumn{9}{|l|}{$\mathrm{Cuba}^{\mathrm{a}}$} \\
\hline 1980 & ... & $\cdots$ & 35.9 & 51.0 & 47.8 & 36.7 & 16.3 & 12.3 \\
\hline 1986 & $\ldots$ & $\ldots$ & 18.6 & 26.5 & 57.1 & 55.4 & 24.3 & 18.1 \\
\hline \multicolumn{9}{|l|}{ Chile } \\
\hline 1989 & 0.3 & 0.4 & 35.7 & 45.9 & 45.3 & 38.1 & 13.2 & 9.1 \\
\hline \multicolumn{9}{|c|}{ Ecuador } \\
\hline 1982 & 13.8 & 15.1 & 35.2 & 53.1 & 28.6 & 16.7 & 14.1 & 7.1 \\
\hline 1990 & 10.4 & 9.8 & 32.2 & 45.9 & 31.9 & 27.5 & 20.6 & 11.9 \\
\hline \multicolumn{9}{|c|}{ Panamá } \\
\hline 1991 & 2.4 & 6.6 & 23.1 & 41.8 & 46.5 & 36.5 & 28.0 & 15.1 \\
\hline \multicolumn{9}{|c|}{ Paraguay } \\
\hline 1982 & 6.1 & 7.7 & 56.1 & 68.7 & 29.6 & 18.7 & 6.3 & 3.1 \\
\hline \multicolumn{9}{|l|}{ Perú } \\
\hline 1981 & 20.8 & 10.5 & 34.5 & 49.1 & 24.5 & 28.2 & 16.8 & 10.2 \\
\hline $1987^{b}$ & 3.3 & 0.8 & 25.9 & 19.7 & 51.8 & 55.4 & 19.0 & 24.1 \\
\hline \multicolumn{9}{|c|}{ República Dominicana } \\
\hline 1991 & 10.5 & 16.9 & 42.9 & 48.4 & 25.5 & 19.3 & 18.1 & 9.6 \\
\hline \multicolumn{9}{|c|}{ Uruguay } \\
\hline 1985 & 1.9 & 3.3 & 40.5 & 52.9 & 47.7 & 37.5 & 9.0 & 5.9 \\
\hline \multicolumn{9}{|c|}{ Venezuela } \\
\hline 1987 & 6.4 & 10.9 & 34.8 & 46.7 & 44.7 & 33.4 & 14.1 & 8.8 \\
\hline
\end{tabular}

Fuente: Valdés y Gomariz (1992 y 1993).

A Sector estatal civil.

B Población de Lima Metropolitana.

"existe una marcada diferenciación en cuanto al tipo de enseñanza por la cual optan hombres y mujeres, observándose en algunos casos menores proporciones de mujeres en las escuelas vocacionales que en las escuelas normales" (Parada, 1991).

La consecuente segmentación entre hombres y mujeres afecta no sólo las posibilidades de desarrollo de las propias mujeres sino también las de la sociedad. Por ejemplo, al final de los años ochenta las mujeres no alcanzaban a formar el $35 \%$ de los graduados en ingeniería en cuatro países cuyo desarrollo productivo es un factor clave para su progreso econó- 
mico y social. ${ }^{7}$ Esto es aún más grave a largo plazo, ya que "el rasgo más relevante del actual ciclo ocupacional es que, más que reducir empleos, el vigoroso dinamismo de las innovaciones tecnológicas caduca habilidades y conocimientos" (CEPAL, 1994a), dejando atrás a las mujeres de manera creciente.

Según estudios que el Banco Mundial ha patrocinado en 15 países de América Latina y del Caribe sobre la participación de las mujeres en la fuerza de trabajo en relación con su nivel educativo y los salarios que reciben, la elección de carrera es también un factor que influye mucho en la discriminación salarial en detrimento de las mujeres. Estos estudios concluyen que la participación femenina en el mercado laboral aumenta marcadamente con el número de años completados en la educación formal, especialmente en la secundaria técnica y superior, y que la educación es un factor absolutamente determinante del nivel de ingreso de las mujeres tanto como de los hombres. Sin embargo, la rentabilidad de la educación en términos de ingresos sigue siendo más baja para las mujeres en los 15 países investigados. Según los autores del estudio, esto no se puede explicar por deficiencias en la formación de los recursos humanos sino principalmente por factores de discriminación en el mercado laboral y por la elección ocupacional (Psacharopoulos y Tzannatos, 1992).

Así, la elección vocacional no sólo es un elemento vital del desarrollo de las personas, sino también influye de manera importante en sus posibilidades de participación social y la calidad de sus condiciones de vida, a través del nivel de sus ingresos. Si aplicamos estos últimos criterios, el análisis de la segmentación de la matrícula femenina en la educación secundaria y superior indica que la mayor presencia de las mujeres en estos niveles no significa necesariamente que "se esté generando un cambio en el status social asignado a cada sexo, aunque puede significar en cierta medida una redefinición de los roles ocupacionales y un cambio cualitativo aún difícil de evaluar" (Rico, 1994).

Ya sea en la enseñanza media profesional o en la educación superior, una gran mayoría de las mujeres elige estudiar asignaturas que prolongan sus tareas tradicionales y "no alteran la división sexual del trabajo desde el punto de vista simbólico ni influyen efectivamente sobre las jerarquías entre los géneros"

\footnotetext{
7 Brasil: $15.2 \%$ en 1988; Colombia: $27.1 \%$ en 1986; Cuba: $34.8 \%$ en 1989; Venezuela: $34.6 \%$ en 1988 (Valdés y Gomariz, 1992 y 1993).
}

(Rico, 1994). Por ejemplo, en países tan distintos como Cuba y Paraguay, en la enseñanza media profesional y técnica las mujeres son mayoritarias en las ramas relacionadas con la salud pública, la economía y el arte; paritarias en la industria química y de alimentos; minoritarias en oficios tradicionalmente masculinos como la metalurgia, la construcción y la agricultura, y absolutamente ausentes de otros como la mecánica, la ebanistería y las artes gráficas (Valdés y Gomariz, 1992 y 1993).

Se confirma en la educación superior que a pesar de los cambios y de una creciente redistribución de la matrícula femenina en una selección más amplia de posibilidades ocupacionales, las mujeres se concentran en las ciencias de la educación, las humanidades, las artes, las ciencias sociales y ciertas áreas de las ciencias de la salud, como enfermería, obstetricia, nutrición y odontología. Hay signos alentadores de que las mujeres están logrando una situación paritaria en administración, economía, arquitectura, urbanismo, derecho y química, consideradas hasta ahora como prestigiosas carreras de tradición masculina. ${ }^{8}$ Por último, tanto las ingenierías como las ciencias naturales y exactas siguen siendo de predominio masculino, más aún si se desagregan por disciplinas los porcentajes de presencia femenina en estas carreras, ${ }^{9}$ con consecuentes exclusiones de las mujeres en la innovación tecnológica y la producción de conocimiento.

En cuanto a la matrícula de las instituciones de formación profesional, la tasa de participación femenina varía en estricta relación con la gama de especialidades ofrecidas, llegando a valores insignificantes cuando se trata de ocupaciones consideradas como masculinas. Por las mismas razones, un estudio reciente sobre la contribución de las mujeres al crecimiento económico de América Latina y del Caribe

\footnotetext{
8 Sin embargo, estudios recientes sugieren que estas carreras empiezan a ser consideradas "opciones para mujeres" (Varela, 1991), lo que parecería llevar "a un descenso sostenido en su prestigio de acuerdo a la impresión de lo que ocurre en el mercado laboral" (Rico, 1994).

9 Si se examina por ejemplo la participación de mujeres en las varias disciplinas del ramo en la matrícula del sistema universitario estatal y privado de Perú, se encuentran en 1986 las cifras siguientes: ingeniería química: $23.9 \%$; pesquera: $22.8 \%$; industrial: $17.1 \%$; civil: $11.2 \%$; geológica: $4.4 \%$; electrónica: $2.8 \%$; minas: $2.2 \%$; mecánica: $0.9 \%$. Si se repite el ejercicio con las ciencias naturales y exactas, se desprende que detrás de cifras casi paritarias en la proporción hombres/mujeres se esconden variaciones importantes según el prestigio de las disciplinas. Así, en Perú, el porcentaje de la matrícula femenina en 1986 era de $53.1 \%$ en química; $43.8 \%$ en ciencias biológicas; $31.4 \%$ en zootecnia; $15.6 \%$ en agronomía, y $8.8 \%$ en física (Valdés y Gomariz, 1992 y 1993).
} 
concluye que en este campo la capacitación, en lugar de abrir nuevas oportunidades y posibilidades de ingresos a las mujeres, las ha orientado hacia ocupacio- nes tradicionales de ingresos bajos, perpetuando así las diferencias de oportunidades productivas para hombres y mujeres (Buvinic y Lycette, 1994).

\section{Ultima reflexión}

Así como el sistema educativo permite la reproducción de los modelos tradicionales, su misma estructura puede alentar el desarrollo de modelos nuevos. Para ello se necesita una voluntad política dispuesta a poner en tela de juicio los contenidos culturales transmitidos por la educación, y la participación de todos los agentes sociales involucrados en la estructura del sistema: autoridades nacionales y educativas, educadores, autores de textos, ilustradores y editores, empleadores, sociedad civil y organizaciones de mujeres. De hecho, en su propuesta de mejoramiento de los sistemas de educación de América Latina y del Caribe, la CEPAL y la UNESCO insisten en la necesidad de efectuar un esfuerzo múltiple para llevar adelante la transformación educacional (CEPAL/UNESCOOREALC, 1992).

En la práctica, se busca modificar un proceso de socialización - que se inicia en la familia, pasa por la escuela y se reafirma en el ambiente social -, en el cual se definen identidades de género que privilegian la diferencia e implican subordinación y relaciones de poder asimétricas. Lo que se busca es transformar estos patrones de referencia y de relación entre los géneros, imaginando un escenario diferente, con roles más flexibles, en los que tanto hombres como mujeres se vean realizados como personas y como ciudadanos y ciudadanas. En la formulación de una propuesta curricular, esto significa corregir los sesgos androcéntricos subyacentes en la teoría y en la práctica de la educación, e identificar sus repercusiones en las condiciones de vida, crecimiento, desarrollo personal, inserción en el mundo laboral y participación social de las alumnas y alumnos.

En resumen, las políticas públicas destinadas a mejorar los frutos de la educación formal de las mujeres deberían apuntar ante todo a apoyar a las mujeres de todos los sectores sociales de la región a transformarse en ciudadanas plenas de la sociedad moderna, con iguales oportunidades tanto en la educación como en el mundo del trabajo. Asimismo, las estrategias propuestas deberían conducir a la desaparición de los estereotipos sexuales en la enseñanza, al mejoramiento de la situación de las niñas y mujeres en los diferentes niveles de la educación formal y no formal, y a la promoción de investigaciones sobre las relaciones recíprocas entre la cultura y la educación, siendo la cultura a la vez matriz y producto de los procesos educativos.

\section{Bibliografía}

Abu Nasr, J., I. Lorfing y J. Mikati (1983): Identification and elimination of sex stereotypes in and from school textbooks. Some suggestions for action in the Arab World, París, Organización de las Naciones Unidas para la Educación, la Ciencia y la Cultura (UNESCO).

Bolivia. Coordinadora de la Mujer (1990): Políticas para la incorporación de la mujer en la estrategia de desarrollo, La Paz.

Bolivia, INE (Instituto Nacional de Estadística) (1989): Encuesta nacional de población y vivienda, 1988. Resultados finales.

Bonilla Castro, Elssy (1991): La mujer colombiana en el contexto de la apertura económica, LC/R.1091, Santiago de Chile, Comisión Económica para América Latina y el Caribe (CEPAL).

Brasil, IBGE (Instituto Brasileño de Geografía y Estadística) (1989): Anuario estatístico do Brasil.

Braslavsky, C. (1984): Mujer y educación. Desigualdades educati- vas en América y el Caribe, Santiago de Chile, Oficina Regional de Educación de la UNESCO para América Latina y el Caribe (OREALC).

Buvinic, Mayra y Margaret Lycette (1994): Women's contributions to economic growth in Latin America and the Caribbean: Facts, experience and options, Women in the Americas: participation and development, Background papers of the regional forum, (Guadalajara, 5 al 7 de abril), México, D.F., Banco Interamericano de Desarrollo (BID)/CEPAL/Fondo de Desarrollo de las Naciones Unidas para la Mujer (UNIFEM).

Caldera, Rosa (coord.) (1990): Estudio comparativo de la revisión de textos escolares de mayor uso en planteles públicos y privados de Guatemala, Panamá y El Salvador, Ciudad de Guatemala, Fondo de las Naciones Unidas para la Infancia (UNICEF)/UNIFEM. 
CEPAL (1984): Aportes para la evaluación del decenio de las $\mathrm{Na}$ ciones Unidas para la mujer y para el diseño de estrategias para el futuro, LC/L. 313 (Conf. 77/4), Santiago de Chile.

(1988): Las mujeres en América Latina y el Caribe: entre los cambios y la crisis, LC/L. 464 (CRM. 4/2), Santiago de Chile.

(1990): Los grandes cambios y la crisis: Impacto sobre la mujer en América Latina y el Caribe, LC/G.1592-P, Santiago de Chile. Publicación de las Naciones Unidas, $\mathrm{N}^{\circ}$ de venta S. 90. II. G. 13.

(1991a): Situación comparativa de la mujer en algunos países del Caribe según determinados parámetros sociales, económicos, demógraficos y legales, LC/G. 1659- LC/CAR/ G. 273, Santiago de Chile.

(1991b): La mujer en América Latina y el Caribe: el desafio de la transformación productiva con equidad, LC/L. 627 (CRM. 5/4, Santiago de Chile.

(1992): Informe del taller sobre mejoramiento del marco legal e institucional para la incorporación de la mujer en el desarrollo en países seleccionados de América Latina, LC/ L, 688, Asunción, 26-27 de agosto, Santiago de Chile.

(1993): Panorama social de América Latina, Edición 1993, LC/G. 1768, Santiago de Chile,

(1994a): La cumbre social: una visión desde América Latina y el Caribe (Nota de la Secretaría), LC/G. 1802 (SES. 25/5), Santiago de Chile.

(1994b): Anuario Estadístico de América Latina y el Caribe 1993, LC/G. 1786-P, Santiago de Chile, Publicación de las Naciones Unidas, $\mathbf{N}^{\circ}$ de venta S. 94 . II. G. 1

(1994c): Mujer y trabajo en los noventa: el significado de los cambios en América Latina y el Caribe, DDR/3, Santiago de Chile, mimeo.

CEPAL /UNESCO-OREALC (1992): Educación y conocimiento: eje de la transformación productiva, LC/G. 1702 (SES. 24/4/ Rev. 1), Santiago de Chile.

Chile, SERNAM (Servicio Nacional de la Mujer) (1992): Análisis de roles y estereotipos sexuales en los textos escolares chilenos, Documentos de Trabajo $\mathrm{N}^{\circ} 8$, Santiago de Chile.

Colombia, DANE (1986): Censo 1985, Bogotá, Departamento Administrativo Nacional de Estadística.

Costa Rica, Ministerio de Cultura, Juventud y Deportes / Ministerio de Educación (1991): Análisis de roles y estereotipos sexuales en textos escolares en Costa Rica, San José, UNI$\mathrm{CEF} /$ unifem.

D’Emilio, Anna Lucía (comp.) (1989): Mujer indigena y educación en América Latina, Santiago de Chile, UNESCO/III.

Ecuador, INEC (1991): V Censo de población IV de vivienda, 1990. Resultados definitivos. Resumen nacional, Quito, Instituto Nacional de Estadística y Censos.

Guatemala, INE (Instituto Nacional de Estadísticas) (1989): Encuesta nacional sociodemográfica.

Hasenbalg, Carlos A. y Nelson Do Valle Silva, (1990): Raça e oportunidades educacionais no Brasil, Fundaçâo Carlos Chagas, Cadernos de Pesquisa, N 73, mayo, Sâo Paulo, Cortez Editora.

Honduras, Secretaría de Planificación, Coordinación y Presupuesto (1988): Censo nacional de población, tomo I.

Laaksonen, Lissa (1991): Análisis de género en libros de texto beliceños, Belice, UNICEF/UNIFEm.

Labourdette, Sergio. D. (1989): Educación/Cultura/Poder, Buenos Aires, Centro Editor de América Latina (CEAL).

León, Irene (1992): Contra la discriminación y el racismo: I Encuentro de Mujeres Negras Latinoamericanas y del Caribe, Separata de ALAI, $N^{\circ} 159$, año XVI, II época, Quito, Agencia Latinoamericana de Información (ALAI).

Letelier Gálvez, María Eugenia (1993): Investigación sobre analfabetismo femenino en Chile. Resultados preliminares, Santiago de Chile, Taller de Acción Cultural.
México, INEGI (Instituto Nacional de Estadística, Geografía e Informática) (1990): Resumen general. XI Censo general de población y vivienda.

Michel, Andrée (1989): Nâo aos estereótipos: vencer o sexismo nos livros para crianças e nos manuais escolares, Sâo Paulo, UNESCO/Conselho Estadual da Condição Feminina de Estado de Sâo Paulo.

Montero, Nancy (cons.) (1993): Estereotipos sexuales en textos y televisión, Enlace, Caracas, Centro de Investigación Social/ Centro de Investigaciones Femeninas (CISFEM).

Naciones Unidas (1992): Situación de la mujer en el mundo 19701990. Tendencias y estadísticas, Estadísticas e indicadores sociales, Serie K, No. 8, Nueva York, Oficina de Estadística. Publicación de las Naciones Unidas, $\mathbf{N}^{\circ}$ de venta 92. XVII. 3.

Nicaragua, INEC (1989): ESDENIC 85, Tabulaciones básicas. vol. I., Características generales de la población, Managua, Instituto Nacional de Estadísticas y Censos.

Panamá, Dirección de Estadística y Censos (1990): Censos nacionales de población y vivienda. Resultados finales básicos.

Parada, Soledad (cons.) (1991): Análisis comparativo de la situación de la mujer en cuatro países de América Latina y el Caribe, LC/R.1039, Santiago de Chile, CEPAL.

Piotti Núñez, Diosma Elena (1990): La escuela primaria como generadora y reproductora de contenidos sexistas en la sociedad uruguaya, Revista del Instituto de la Mujer, Montevideo, Ministerio de Educación y Cultura/UNICEF.

Psacharopoulos, George y Zafiris Tzannatos (eds.) (1992): Case Studies on Women's Employment and Pay in Latin America, Washington, D.C., Banco Mundial.

Rico, María Nieves (1994): Formación de recursos humanos femeninos: un desafío para la equidad, Santiago de Chile, CEPAL, Unidad Mujer y Desarrollo, mimeo.

Rivera, Marcia (1993): El Caribe, los movimientos de mujeres y los estudios de género, Claudia Serrano (coord.), La investigación sobre la mujer en América Latina, Santo Domingo, República Dominicana, Instituto Internacional de Investigaciones y Capacitación para la Promoción de la Mujer (INSTRAW) /UNESCO/Centro de Investigación para la Acción Femenina (CIPAF)

Rossetti, Josefina (1988): La educación de las mujeres en Chile contemporáneo, en CEM (Centro de Estudios de la Mujer), Mundo de mujer: continuidad y cambio, Santiago de Chile, Ediciones CEM.

(1992): Educación y empleo: ayudar a las mujeres a formular un buen proyecto vocacional y laboral, en María Antonia Gallart (comp.), Educación y trabajo: desafios y perspectivas de investigación y politicas para la década de los noventa, vol. II, Montevideo, Red Latinoamericana de Educación y Trabajo, Centro Internacional de Investigaciones para el Desarrollo (CiID)/Centro de Estudios de Población (CENEP)/Centro Interamericano de Investigación y Documentación sobre la Formación Profesional (CINTERFOR).

Schiefelbein, E. y S. Peruzzi (1991): Oportunidades de educación para la mujer. El caso de América Latina y el Caribe, Boletín del proyecto principal de educación en América Latina y el Caribe, $\mathrm{N}^{\circ} 24$, Santiago de Chile, UNESCO/OREALC.

Subirats, Marina (1990): La construcción de una educación no sexista, ponencia presentada en el seminario Las reformas educativas en las transiciones democráticas, Informe (Santiago de Chile, PIIE/ICI, 6-8 de noviembre).

Torres, Rosa María (1993): La madre en los textos escolares, Enfoques de mujer, $\mathrm{N}^{\circ} 28$, Asunción, GEMPA.

UNESCO (1992a): Situación educativa de América Latina y el Caribe, 1980-1989, Santiago de Chile, UNESCO/OREALC. (1992b): Anuario estadístico 1992, París.

(1992c): Informe mundial sobre la educación 1991, París.

UNICEF/Chile, MIDEPLAN (Ministerio de Planificación y Cooperación) (1993): La impresión de las cifras. Niños, mujeres, jóvenes y adultos mayores, Santiago de Chile, UNICEF/Oficina de Area para Argentina, Chile y Uruguay. 
Valdés, Teresa y Enrique Gomariz (coords.) (1992): Mujeres latinoamericanas en cifras, 6 vols. (Brasil, Costa Rica, Cuba, Chile, Ecuador y Guatemala), Madrid/Santiago de Chile, Ministerio de Asuntos Sociales (España), Instituto de la Mujer/ Facultad Latinoamericana de Ciencias Sociales (FLACSO-Chile).

(1993): Mujeres latinoamericanas en cifras, 8 vols. (Bolivia, Colombia, Panamá, Paraguay, Perú, República Dominicana, Uruguay y Venezuela), Madrid/Santiago de Chile, Ministerio de Asuntos Sociales (España), Instituto de la Mujer/ FLACSO-Chile.
Varela, Carmen (1991): Las mujeres en la universidad uruguaya de los '80: una reflexión a partir de la feminización de su matrícula, Montevideo, Grupo de Estudios sobre la Condición de la Mujer en el Uruguay (GRECMU), mimeo.

Venezuela, Oficina Central de Estadística e Informática de la Presidencia de la República (1990): Anuario estadístico.

Zúñiga, Madeleine (1989): Situación educativa de la mujer indígena. Caso de Perú en Anna Lucía D'Emilio (comp.), Mujer indígena y educación en América Latina, Santiago de Chile, UNESCO/III. 